\title{
Heavy-duty transmission gear shift investigation by virtual prototypes
}

\author{
Ales Prokop ${ }^{1}$, Pavel Kucera ${ }^{2}$, Kamil Rehak ${ }^{3}$ \\ Brno University of Technology, Brno, Czech Republic \\ ${ }^{1}$ Corresponding author \\ E-mail: ${ }^{1}$ prokop.a@fme.vutbr.cz, ${ }^{2}$ kucera@fme.vutbr.cz, ${ }^{3}$ rehak@fme.vutbr.cz
}

Received 24 April 2018; accepted 1 May 2018

DOI https://doi.org/10.21595/vp.2018.19947

Check for updates

Copyright (C) 2018 Ales Prokop, et al. This is an open access article distributed under the Creative Commons Attribution License, which permits unrestricted use, distribution, and reproduction in any medium, provided the original work is properly cited.

\begin{abstract}
This paper deals with application of virtual prototype to the heavy-duty vehicles gearbox concept. Used methodology was developed and validated on the single stage gearbox concept. Afterwards the virtual prototype was applied to complex gearbox and extended for gear shift. Gear shift has a significant influence on comfort of vehicle and also for its lifetime. The gear shift process has to be fast and smooth as much as possible, which is very difficult. This paper deals with using virtual prototype to see the effect of different gear shift process on the vibration of gearbox. The validation by the experimental approach of gearshift has not been performed yet.
\end{abstract}

Keywords: vibration, gearbox, numerical simulation, gear shift.

\section{Introduction}

Due to increasing interest of environment, the hybrid and electric vehicles are developed much faster, then cars with standard combustion engine. The electric vehicles are considerably different then hybrid and vehicles with combustion engine. The automatic transmissions for hybrid and cars with combustion engine have been developed for years. The gearshift is performed fast and precisely. With increasing number of cars, the transmissions manufacturers are focused on further optimization during process of gears shift and also for the optimization of using materials for whole transmission with respecting limits of noise and vibration. The decreasing weight positively affect the car consumption, which is one of the key parameters for customer. On the other side the reducing of gearbox wall thickness can significantly increase vibration and emitted noise, which negatively affects the passenger comfort.

The developing phase of each product is time consuming and also expensive. The manufacture of prototype parts are several times more difficult then following serial production. During the developing phase several modifications are compared. In case when the developing phase is dominantly performed by using experimental approach, the whole process is getting more expensive in comparison of the computational approach, also takes a lot of time and therefore the final product is not competitive on the market. For that reason, the computational approach has irreplaceable place in developing phase. On the other side the used methodology and the final product have to be tested to confirm that fulfil requirements.

\section{Methods}

This paper deals with application of virtual prototype to the heavy-duty gearbox. First the methodology was developed on the single stage gearbox. The single stage gearbox is used for investigation because of relatively simplified construction which enables wide range of modification [1]. Each part of methodology was evaluated by technical experiment. The whole process of creating methodology consists of modal analysis, harmonic analysis and multibody simulation. The methodology combines multibody simulation software ADAMS and finite element method (FEM) software Ansys. The FEM was used to get input data for the parametrical open code, which was written in software ADAMS. The sensitivity study on input parameters were performed on the virtual prototype of single stage gearbox [2]. 
The code enables to include flexible bodies, bearing stiffness, gear mesh stiffness, backlash, variable input speed and torque. The opened code can be modified to wide spectrum of gearbox.

For application of virtual prototype to heavy-duty gearbox the input parameters have to be modified. The flexible bodies of shafts and housings were performed by using Craig Bampton modal reduction. The stiffness of each bearing has to be calculated, but only one rolling segment was calculated and then converted to the whole bearing [3].

The dominant excitation of the gearbox is due to gear mesh phenomena [4]. For that reason the gear meh stiffness has to be calculated with respect of number of teeth and parameters of each gears pair, see Fig. 1. Moreover, the stiffness is changing during transmitted torque, thus the whole range of torque has to be calculated for each gear pair, the gear mesh stiffness without any tooth damage for one gear pair is shown in Fig. 2 and corresponds to the results mentioned in [5]. The backlash can be included for each gear pair separately, which corresponds to tolerances of manufacturing. To the input and output shaft can be applied velocity and torque parameters, which can have also irregularities based on the functional principle of the combustion engine, which enables to incorporate another dominant source of excitation [6].

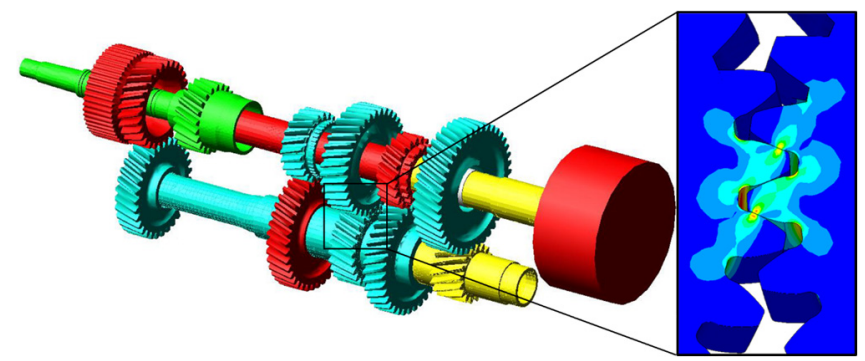

Fig. 1. Gearbox concept and gear mesh Von Mises stress distribution for one gear pair

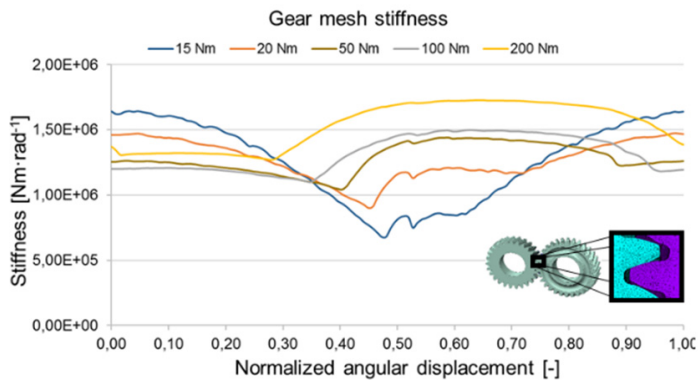

a)

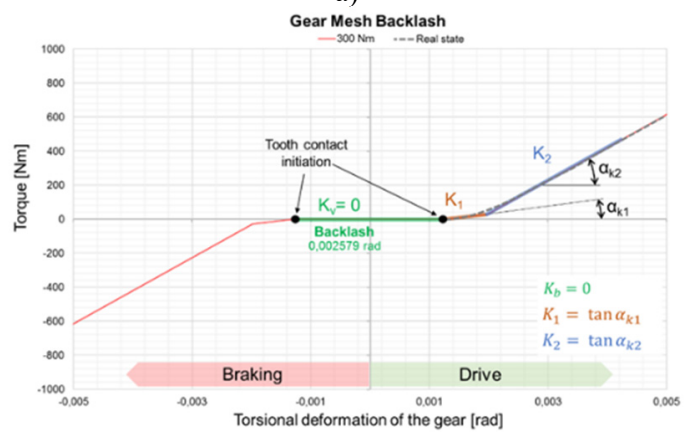

b)

Fig. 2. Gear mesh stiffness and gear mesh backlash for one gear pair

This virtual prototype of heavy-duty gearbox, which is based on the open code of single stage gearbox, is modified to enable shifting of gear. The new function is added to set the time 
dependency of hydraulic pressure in clutch, which is in virtual prototype normalized to clutch activation function, see Fig. 3.

\section{Results}

The virtual prototype without adding options of gear shift enabled to simulate steady states with results for each selected gear or run up and run down for different gear. The usage of virtual prototype with adding shifting functionality is wider. The effect of shifting time, different dependency of hydraulic pressure, different cross of couplings can be investigated without necessity to use the real prototypes. The surface normal velocity, forces in bearings can be evaluated. In this study two different shifting profiles are compared, see Fig. 3. In the first variant the full clutch activation is done in time range from 4 to $5.5 \mathrm{sec}$, from 4 to $4.75 \mathrm{sec}$ in second case.

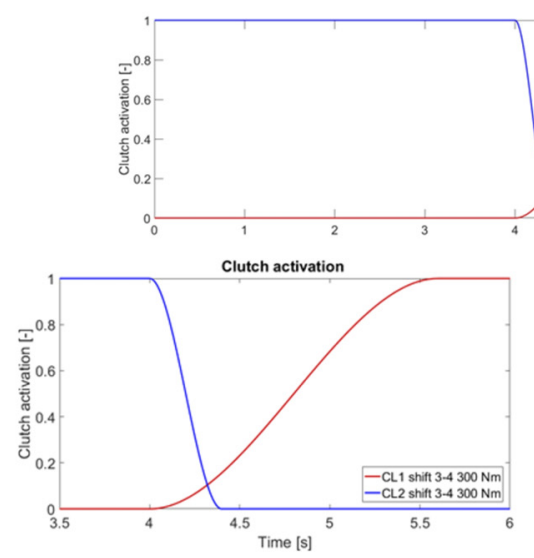

a)
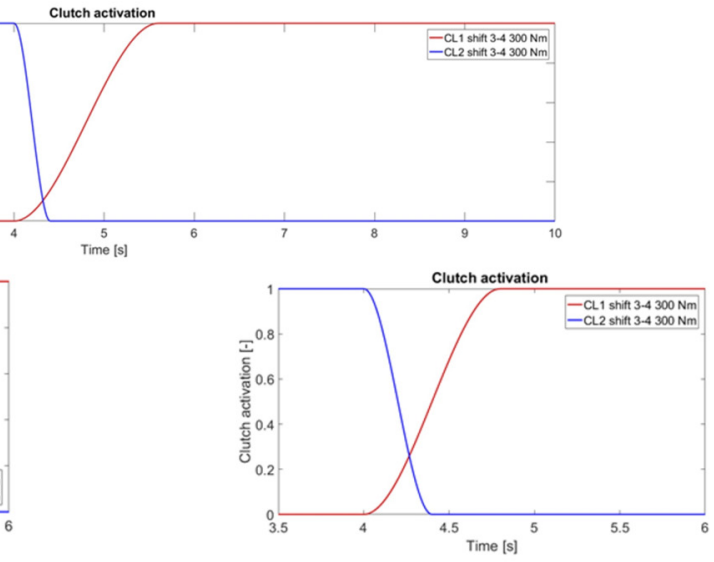

b)

Fig. 3. Time dependency of normalized clutch activation for: a) first variant, b) second variant

Based on change of the gear ratio during shifting in combination with inertia masses, the significant change of torque and speed occurs. With decreasing time of the clutch activation, the carried torque amplitude is higher. In Fig. 4 is shown clutch torque dependency for mentioned two variants of the shift profile. It is possible to observe the torque exchange between clutch 1 and clutch 2 .

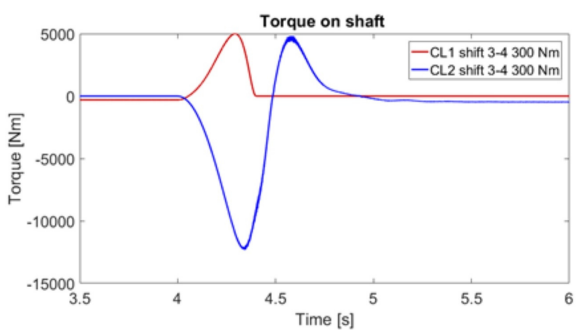

a)

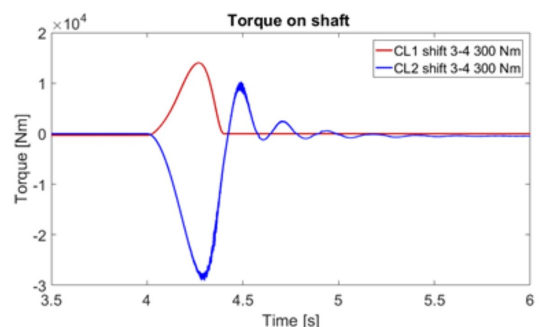

b)

Fig. 4. Torque dependency during clutch activation for: a) first variant, b) second variant

Minimizing of the shifting time causes the impact-like behavior of the carried torque, which is transformed to reaction forces on gears. This type of excitation is transferred to the shafts, bearings and also to gearbox housing. Mentioned impact during shifting has wide frequency range excitation character, which is possible to observe between time 4 and 5 in Fig. 5, where surface normal velocity in certain point on gearbox housing is plotted. Multispectra also show the excitation frequencies, based on functional principle of the transmission. The dominant excitation 
is done by time varying gear mesh stiffness. This tooth frequencies are detectable after shifting, the main reason of this phenomenon is due to direct connection of input and output shaft while the previous gear is activated. It means that total gear ratio value is changing during shifting from 1 to different.

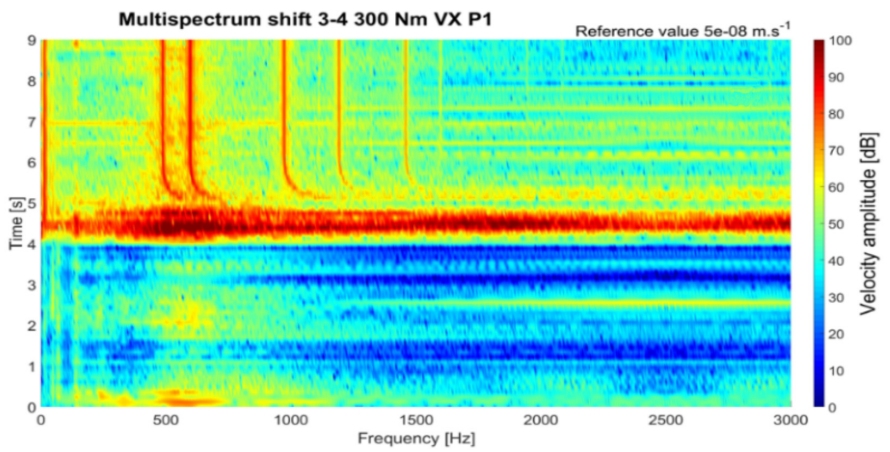

a)

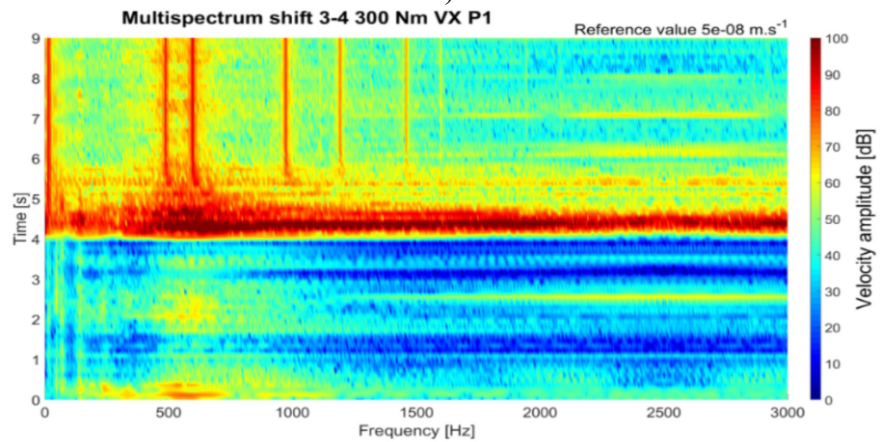

b)

Fig. 5. Multispectra surface normal velocity for: a) first variant, b) second variant

With decreasing time of the clutch activation, the amplitude of surface normal velocity is higher, see Fig. 6. This can be fixed by proportional function, implemented to the clutch activation function, which is planned for the future research.
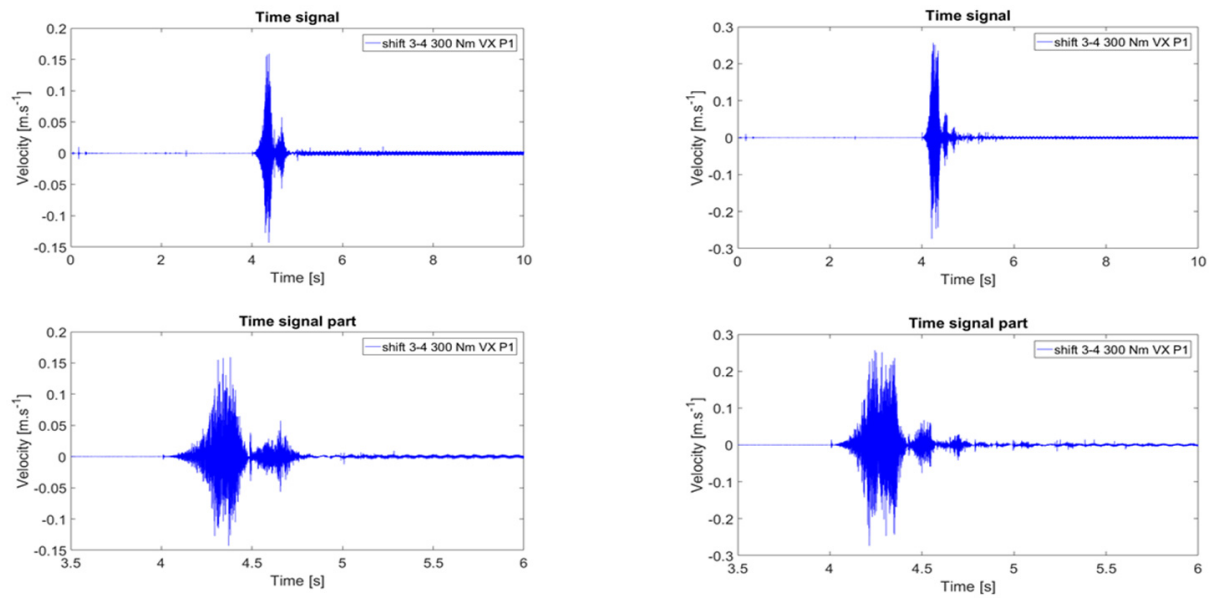

a)

b)

Fig. 6. Surface normal velocity for: a) first variant, b) second variant 


\section{Conclusions}

Transmission dynamic modelling using virtual prototypes becoming recently spread approach how to solve the dynamic behavior of the very complex transmission, including mentioned transient simulations. The whole methodology, which is based on the combination of FEM and MBS, is developed on the single stage gearbox. One of the most important advantages of this methodology is the open code and an easy way of modification with aim to use it for wide range of transmissions. The possibility to use results as input from FEM is very useful which enables to include own geometry modification. This article presents results and possibilities of using this methodology on the more complex transmission concepts. Nonetheless, this concept of gearbox is developed, and the methodology is applied as another option to gain important information without the need to create high number of prototypes.

\section{Acknowledgements}

The research leading to these results has received funding from the Ministry of Education, Youth and Sports under the National Sustainability Programme I. (Project LO1202) and with help of the Project FSI-S-17-4104 granted by Specific University Research of Brno University of Technology. The authors gratefully acknowledge this support.

\section{References}

[1] Loutas T. H., Sotiriades G., Kalaitzoglou I., Kostopoulos V. Condition monitoring of a single-stage gearbox with artificially induced gear cracks utilizing on-line vibration and acoustic emission measurements. Applied Acoustics, Vol. 70, 2009, p. 1148-1159.

[2] Prokop A., Rehak K., Zubik M., Novotny P. Experimental validation of the gearbox NVH parameters. Journal of Middle European Construction and Design of Cars, Vol. 13, Issue 2, 2015, p. 16-21.

[3] Razpotnik M., Bischof T., Boltežar M. The influence of bearing stiffness on the vibration properties of statically overdetermined gearboxes. Journal of Sound and Vibration, Vol. 351, 2015, p. 221-235.

[4] Tuma J. Vehicle Gearbox Noise and Vibration: Measurement, Signal Analysis, Signal Processing and Noise Reduction Measures. John Wiley, Chichester, 2014, p. 243.

[5] Kiekbush T., Sppok D., Bernd S., Ian H. Calculation of the combined torsional stiffness of spur gears with two- and three-dimensional parametrical FE models. Journal of Mechanical Engineering, Vol. 57, 2011, p. 810-818.

[6] Drápal L., Šopík L. Influence of crankshaft counterweights upon engine block load. Proceedings of the International Conference on Transport Means, 2016, p. 809-814. 